\title{
Spatial variations in dietary fibre intake among women in England from the UK Women's Cohort Study
}

\author{
C. E. Rycroft, M. A. Morris, C. E. Evans and J. E. Cade \\ Nutritional Epidemiology Group, School of Food Science and Nutrition, The University of Leeds, Leeds, LS2 9JT
}

Despite regional variations in health patterns throughout the United Kingdom ${ }^{(1)}$ and recognition that some health inequalities are linked to inequalities in nutrition ${ }^{(2)}$, there is relatively little evidence about small scale geographical differences in diet. The UK Women's Cohort Study ${ }^{(3)}$ provides an opportunity to explore such differences as it contains both dietary and geographic data. Fibre in the diet is associated with health benefits including a reduced risk of coronary heart disease ${ }^{(4)}$, some cancers ${ }^{(5,6)}$ and type 2 diabetes mellitus ${ }^{(7)}$. This study considers whether there are regional variations in dietary fibre intake among women in England contributing to differences in diet.

Dietary fibre intake by fraction (total fibre, soluble fibre and insoluble fibre) and by English region of residence was explored using mapping techniques. The relationship between total dietary fibre intakes and region of residence was investigated using ordinary least squares regression modelling.

Choropleth maps indicated spatial variations in mean intakes of each fibre fraction. Regression modelling showed a small positive, significant difference in total fibre intake for the North East, the East Midlands and the South West, compared to Yorkshire and the Humber, the region with mean total fibre intakes closest to the mean for the whole sample $(26 \cdot 2 \mathrm{~g} / \mathrm{day})$.

\begin{tabular}{|c|c|c|c|}
\hline \multirow[b]{3}{*}{ Independent Variable: Region of Residence } & \multicolumn{3}{|c|}{ Dependent variable: Total fibre intake ( $\mathrm{g} /$ day) } \\
\hline & Multivariate Model, $n$ & & \\
\hline & Regression Coefficient & $95 \% \mathrm{CI}$ & $p$ value \\
\hline Yorkshire and the Humber & ref & & \\
\hline North East & 0.76 & 0.16 to 1.35 & 0.01 \\
\hline North West & $-0 \cdot 19$ & -0.62 to 0.23 & 0.38 \\
\hline East Midlands & 0.51 & 0.06 to 0.96 & 0.03 \\
\hline West Midlands & 0.09 & -0.36 to 0.54 & 0.70 \\
\hline East of England & 0.20 & -0.23 to 0.63 & 0.36 \\
\hline Greater London & -0.34 & -0.75 to 0.08 & $0 \cdot 11$ \\
\hline South East & 0.32 & -0.06 to 0.69 & $0 \cdot 10$ \\
\hline South West & 0.78 & 0.38 to 1.18 & $<0.01$ \\
\hline Proportion of variance explained by the model, $\mathrm{R}^{2}$ & 0.5349 & & \\
\hline
\end{tabular}

Multivariate Model adjusted for age, sweaty activity, alcohol intake, energy intake, quintile of index of multiple deprivation, smoking status, dietary pattern and marital status.

The study shows that there are spatial variations in women's dietary fibre consumption throughout England among the UK Women's Cohort Study. Although small, these differences in dietary fibre intake between the regions may be important for health outcomes.

1. NCIN Cancer eAtlas $2011 \mathrm{http}: / /$ www.ncin.org.uk/cancer_information_tools/eatlas/default.aspx. (accessed June 2012).

2. Smith GD, Brunner E. (1997) Proc Nutr Soc 56(1A):75-90

3. Cade JE, Burley VJ, Greenwood DC et al. (2004) Public Health Nutr 7(7):871-8.

4. Liu SM, Stampfer MJ, Hu FB et al. (1999) Am J Clin Nutr 70(3):412-9.

5. Cade JE, Burley VJ, Greenwood DC et al. (2007) Int J Epidemiol 36(2):431-8.

6. Aune D, Chan DSM, Lau R et al. (2011) Br Med J 343:d6617.

7. Montonen J, Knekt P, Jarvinen R et al. (2003) Am J Clin Nutr 77(3):622-9. 